\title{
Physical Properties of Polyacrylamide/Polyvinylalcohol Silica Nanocomposites
}

\author{
Dalia E. Abulyazied, Nahla A. Mansour, Azza M. Mazrouaa* and Manal G. Mohamed
}

Egyptian Petroleum Research Institute, Petrochemical Department, Polymer Lab, Nasr City, Cairo, Egypt

\begin{abstract}
In this paper, samples of Polyacrylamide (PAAm) nanosilica nanocomposites were prepared having different concentration of nanosilica $(0.125,0.25$, and 0.5$)$. Polyacrylamide (PAAm) and poly (vinyl alcohol) (PVA) were blended with different ratio $(3 / 1,1 / 1,1 / 3)$ using solution-cast technique. The prepared films were characterized by Fourier transform infrared (FTIR), X-ray diffractions (XRD) and scanning electron microscopy (SEM). FTIR spectra showed the presence of hydrogen bonding between- $\mathrm{CONH}_{2}$ groups in PAAm and $-\mathrm{OH}$ group in PVA and confirm the hydrophilic nature of the blends. X-ray diffractions shows the presence of a strong broad peak centered at $22^{\circ}(2 \theta)$ confirms the amorphous nature of silica which is supposed to be the characteristic of $\mathrm{SiO}_{2}$. The results obtained from different experimental techniques were supported by SEM image analysis. The thermal stability of the nanocomposites enhanced by increasing the silica content in the blend. The DC electrical conductivity was studied for all prepared samples. It was found that the conductivity increase by increasing silica content as well as, increased by increasing the wt\% of PVA.
\end{abstract}

Keywords: Polyacrylamide (PAAm), Polyvinylalcohol (PVA), Nanosilica $\mathrm{SiO}_{2}$, Blend, Thermal stability TGA and Electrical conductivity.

\section{INTRODUCTION}

Polymer matrix reinforced by nanofiller is probably the most commonly used form of composites in structural application, such as air craft's, boats, automobiles [1]. A single material may not meet all the requirements necessary for a potential filler. Since the final properties of the composites are controlled by the properties and proportion of the component materials, the choice of the filler plays a very important role in polymer composites [2, 3].

Polyacrylamide (PAAm) nanosilica inclusions composites were prepared having different ratios of nanosilica. The silica inclusions were either modified or unmodified. The nanocomposite films were characterized by transmission electron microscope (TEM) and infrared spectroscopy (IR). The dielectric behaviour of the composites had been investigated as a function of the concentration of the nanosilica inclusions. The results show that the dielectric constant and dielectric loss of the nanocomposites are smaller than those obtained for the neat polymer. As the concentration of the surface-modified nanosilica inclusions increases, the dielectric constant decreases. This behaviour may be attributed to the successful interaction between the polymer and the surface of the nanosilica inclusions [4]. Poly (vinyl alcohol) (PVA) is a low cost hydrophilic polymer, and shows potential application as hydrogel, polyelectrolytes, optical

*Address correspondence to this author at the Egyptian Petroleum Research Institute, Petrochemical Department, Polymer Lab, Nasr City, Cairo, Egypt; Tel: +20 102372 636; Fax: +20 222747 433;

E-mail: azza_mazroua2005@yahoo.com materials, and biomaterials [5-7]. A large number of research groups have reported on the fabrication of organic inorganic hybrid membranes containing inorganic oxides $\mathrm{SiO}_{2}$, which has contributed to the improvement of chemical and mechanical properties. In most cases, inorganic oxides were added into the polymer matrix using a sol-gel process from inorganic precursors [8-11]. As we all know that the homogeneous distribution of inorganic oxides in the resulting organic-inorganic hybrid membranes can increase the mechanical properties, however the interaction of polymer and inorganic nanoparticles also plays a great role in the increase of the properties of the hybrid materials [12]. The crystallinity decreased with increased silica content and changes the morphology and structure due to the formation of cross-linking [13].

Experimental investigations were carried out in polymer blends have gained significant importance, studies on several polymer blends [14], and although the formation of a single phase, homogeneous, compatible blends is thermodynamically unfavourable. Several experimental techniques have been employed to study the polymer blends such as dielectric relaxation $[15,16]$, nuclear magnetic resonance $[17$, 18] and electron spin resonance [19]. Thermally stimulated discharge current (TSDC) studies in polyacrylamide(PAAm) and the electrical conduction phenomena and TSDC studies in polyvinyl alcohol(PVA) in the low temperature have been reported earlier [20-24]. The thermally stimulated luminescence (TSL) in PAAm-PVA blends have been made and results are correlated with the results 
obtained from differential scanning calorimetry (DSC) and Optical microphotography [25]. Thermal behavior of poly (vinyl alcohol)-graft-polyacrylamide copolymers (PVA-g-PAAm), so-called intramolecular polymerpolymer complexes was studied. Complete compatibility of PVA and PAAm through hydrogen bonding is realized in the range of the graft lengths not exceeding some critical value. The content of adsorbed and trapped water in graft copolymers reflects some features of PVA-g-PAAm structure depending on the graft lengths [26].

The aim of the research focuses on the preparation of PAAm in presence of different concentration of nanosilica $(0.125,0.25$ and 0.5$)$ and preparation of PAAm/PVA blend nanocomposites with different ratio $(3 / 1,1 / 1,1 / 3)$.Furthermore, morphological studies of forming nanocomposites have been conducted using $X$-ray diffraction (XRD) and scanning electron microscopy (SEM) techniques. The effects of adding different ratio of PVA and concentration of $\mathrm{SiO}_{2}$ on thermal stability and the electrical conductivity of PAAm was also studied.

\section{EXPERIMENTAL}

\subsection{Materials}

The raw materials used in our experiments are available as commercial products. Polyvinyl alcohol
(PVA) (mol. wt $=5417)$, Polyacrylamide $(P A A m)$ in the form of powder $\left(\mathrm{mol}\right.$. wt $\left.=5 \times 10^{6}\right)$.Silica nanoparticle $27 \mathrm{~nm}$.

\subsection{Preparation of PAAm/PVA Blend}

Both PAAm and PVA are water soluble resins. Then polymer blends of PAAm-PVA with different ratio are obtained by evaporation of a solution of these polymers on petri dishes, to yield stable polymer blend transparent films as shown in (Table 1).

\subsection{Preparation of PAAm/PVA/ Silica Nanoparticle (Fumed Silica $\mathrm{SiO}_{2}$ )}

Different weight percent $(0.125,0.250,0.500 \mathrm{wt} \%)$ of silica nanoparticle was added to PAAm and PAAm/PVA blends in sonicator at $30 \mathrm{~min}$ at room temperature as shown in (Table 1).

\subsection{Characterization}

\section{Fourier Transform Infrared (FTIR)}

IR measurement was carried out with $\mathrm{KBr}$ methods PAAm/PVA blends and PAAm/PVA nanocomposite samples $(2 \mathrm{mg})$, which was dried overnight at $60^{\circ} \mathrm{C}$ under reduced pressure, were mechanically wellblended with $100 \mathrm{mg}$ of $\mathrm{KBr}$. The thickness of the $\mathrm{KBr}$ disk was $0.5 \mathrm{~mm}$. The $\mathrm{KBr}$ disk of the mixed powder was desiccated for $24 \mathrm{~h}$ at $110^{\circ} \mathrm{C}$ under reduced

Table 1: Composition of PAAm/PVA Blends and their Silica Nanocomposites

\begin{tabular}{|c|c|c|c|}
\hline Sample Code & PAAm & PVA & Nanosilica Conc. \\
\hline Mo & $80 \mathrm{gm}$ & - & 0 \\
\hline M1 & $80 \mathrm{gm}$ & - & 0.125 \\
\hline M2 & $80 \mathrm{gm}$ & - & 0.250 \\
\hline M3 & $80 \mathrm{gm}$ & - & 0.500 \\
\hline MAO & $60 \mathrm{gm}$ & $20 \mathrm{gm}$ & 0 \\
\hline MA1 & $60 \mathrm{gm}$ & $20 \mathrm{gm}$ & 0.125 \\
\hline MA2 & $60 \mathrm{gm}$ & $20 \mathrm{gm}$ & 0.250 \\
\hline MA3 & $60 \mathrm{gm}$ & $20 \mathrm{gm}$ & 0.500 \\
\hline MB0 & $40 \mathrm{gm}$ & $40 \mathrm{gm}$ & 0 \\
\hline MB1 & $40 \mathrm{gm}$ & $40 \mathrm{gm}$ & 0.125 \\
\hline MB2 & $40 \mathrm{gm}$ & $40 \mathrm{gm}$ & 0.250 \\
\hline MB3 & $40 \mathrm{gm}$ & $40 \mathrm{gm}$ & 0.50 \\
\hline MCO & $20 \mathrm{gm}$ & $60 \mathrm{gm}$ & 0 \\
\hline MC1 & $20 \mathrm{gm}$ & $60 \mathrm{gm}$ & 0.125 \\
\hline MC2 & $20 \mathrm{gm}$ & $60 \mathrm{gm}$ & 0.250 \\
\hline MC3 & $20 \mathrm{gm}$ & $60 \mathrm{gm}$ & 0.50 \\
\hline
\end{tabular}


pressure and then its IR spectrum was recorded with a Shimadzu FTIR-4200 spectrometer using a disk of 100 $\mathrm{mg} \mathrm{KBr}$ as a reference. The maximum intensity of the $\mathrm{IR}$ absorption band was determined by the baseline method.

\section{$X$-Ray Diffraction (XRD)}

X-ray diffraction (XRD) patterns of the sheet samples were recorded on X-ray diffractometer (D/Max2500VB2+/Pc, Rigaku Company, Tokyo, Japan) with area detector operating at a voltage of $40 \mathrm{kV}$ and a current of $50 \mathrm{~mA}$ using Cu Ka radiation $(\lambda=0.154 \mathrm{~nm})$. The scanning rate was $1 \%$ min and the scanning scope of $2 \theta$ was from $5^{\circ}$ to $50^{\circ}$ at room temperature.

\section{Scanning Electron Microscope (SEM)}

The micro structure of samples was examined from micrographs taken with (SEM, TOPCON ABT150S, Japan). Samples were mounted on metal grids and coated with gold under vacuum before observation.

\section{Thermogravimetric Analysis (TGA)}

TGA measurements were carried out on a Netzsch DSC 204 (Germany). Traces of each sample were obtained from the second heating run at a constant rate of $10^{\circ} \mathrm{C} / \mathrm{min}$, after the first run of heating up to $700^{\circ} \mathrm{C}$ and cooling naturally at room temperature under nitrogen atmosphere.

\section{The Electrical Conductivity Measurements}

The conductivity measurements were carried out by four-probe technique recorded by Keithley electrometer type $6517 \mathrm{~A}$. The pellet used in this measurement is placed between two copper electrodes; which were connected to the two terminal of Keithley electrometer. The samples were pressed into pellets of $1.33 \mathrm{~cm}$ diameter and $1 \mathrm{~mm}$ thickness in a hydraulic press
(Kimaya Engineers; India; Model WT-324) at five metric ton pressure.

\section{RESULTS AND DISCUSSION}

\subsection{Fourier Transform Infrared (FTIR)}

The FTIR spectra of all samples almost was similar so the sample MB3 was chosen. The band at $3435 \mathrm{~cm}$ ${ }^{1}$ corresponded to the $\mathrm{O}-\mathrm{H}$ stretching vibrations and $\mathrm{N}$ $\mathrm{H}$ stretching primary amine (Figure 1). The peak at $1663 \mathrm{~cm}^{-1}$ due to $\mathrm{C}=\mathrm{O}$ of PAAmAmorphous silica exhibits a relatively strong peak around the peaks at 1112 and $804 \mathrm{~cm}^{-1}$ due to the O-Si-O asymmetric and symmetric stretching modes, respectively. Addition of PVA into PAAm polymer matrix, bands of PAAm at $3124 \mathrm{~cm}^{-1}$ and $3248 \mathrm{~cm}^{-1}$ which are symmetric and asymmetric stretching vibration of $-\mathrm{NH}_{2}$ group involved in inter molecular interaction of hydrogen bond coupled with $-\mathrm{OH}$ group of PVA at $3145 \mathrm{~cm}^{-1}$ and $3301 \mathrm{~cm}^{-1}$ $[27,28]$.

\subsection{X-Ray Diffraction}

For clarification, the XRD of MB3 sample was examined and shown in (Figure 2) to confirm the presence of nanosilica. A strong broad peak centered at $(2 \theta) 22^{\circ}$ confirms the amorphous nature of silica which is supposed to be the characteristic of $\mathrm{SiO}_{2}$. Due to thermochemical process, the crystalline particles transforms into amorphous silica which is indicated by broad peak [27, 28].

\subsection{Scanning Electron Microscope (SEM)}

In general, the nanosilica particle is shown in Figure 3a. The morphology of nanosilica is observed as spherical in shape [29] and it exhibits the agglomerated particle with uniform size in the range of $90 \mathrm{~nm}$. The

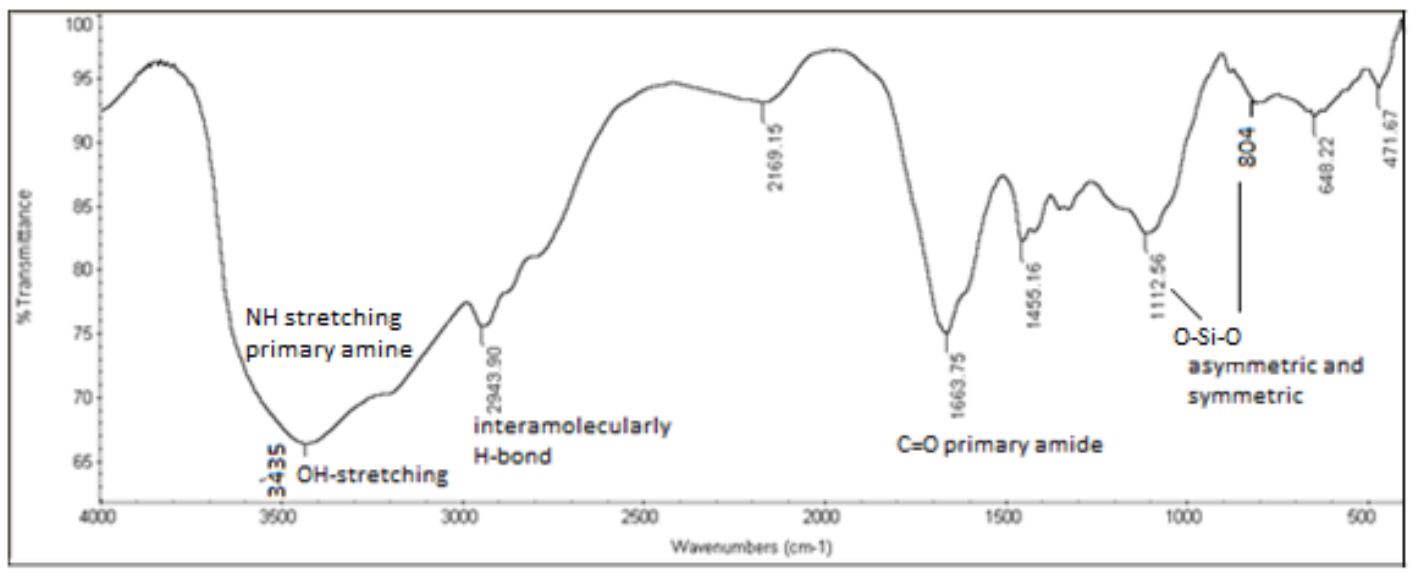

Figure 1: FTIR spectrum of MB3. 


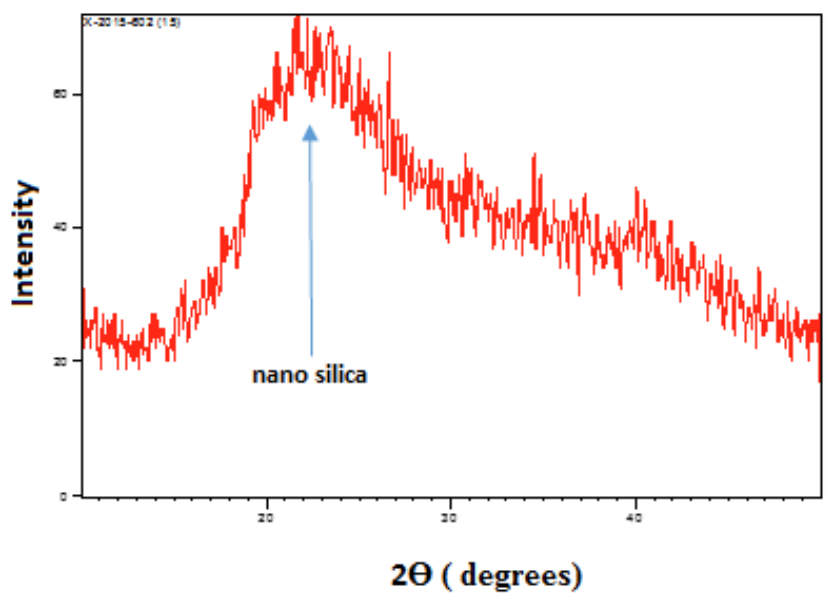

Figure 2: XRD spectrum of MB3 sample.

presence of the nano-sized spherical particles leads to a highly porous structure. The scanning electron microscopy (SEM) shows microstructure morphologies of polyacrylamide PAAm and polyvinylalcohol PVA as shown in (Figure 3b, c). SEM images for PAAm show smooth and homogeneous surface with some strips but PVA show as sponge structure. Formation of homogeneous blends was mostly caused by the interaction of hydrogen bonds between the functional groups of blend components [30]. As shown in (Figure 3d-f), the blend surfaces have heterogeneous mesh type morphology. This is possibly due to PVA, linear polymer, cross-linked with PAAm may form clusters/domains of chains bonding via hydrogen bond between $-\mathrm{CONH}_{2}$ groups in PAAm and $-\mathrm{OH}$ group in PVA. At low PVA content, cross-linking density is low. So the network chains have good movement and arrange themselves to make mesh type of domain network. As PVA content increases, the mesh/domain size keeps shrinking. From SEM micrograph, the interaction between PAAm and PVA is much greater than others and the surface of $1 / 1$ blend ratio is rougher than the other blends. This also indicates the enhancement in thermal and electrical properties [31]. In addition the presence of nanosilica increase the homogeneity mesh type morphology of the blend surface. Formation of homogeneous blends was mostly caused by the interaction of hydrogen bonds between the functional groups of blend components.

\subsection{Thermal Stability and Degradation}

The thermal degradation behaviour of pure PAAm and their blend samples of PAAm/PVA in presence of different concentration of nanosilica were examined by TGA. The addition of nanoparticles can be used to manipulate the optical, thermal, magnetic, and electric properties of polymers [32, 33]. Compared with pure polymers, the polymer composite materials containing silica nanoparticles may exhibit more satisfactory thermal stability, toughness and strength owing to the effect of physical adsorption such as hydrogen bond formation [34, 35].

The effect of different concentration of nanosilica on the thermal stability of PAAm was shown in (Figure 4), the first stage decomposition was due to the loss of absorbed water molecules until $280^{\circ} \mathrm{C}$ and the next stage decomposition included the major weight losses. It was observed that with increasing the concentration of nanosilica in PAAm increase $T_{10}, T_{50}, T_{\max }$ and also the char residue \% respect in compared with pure
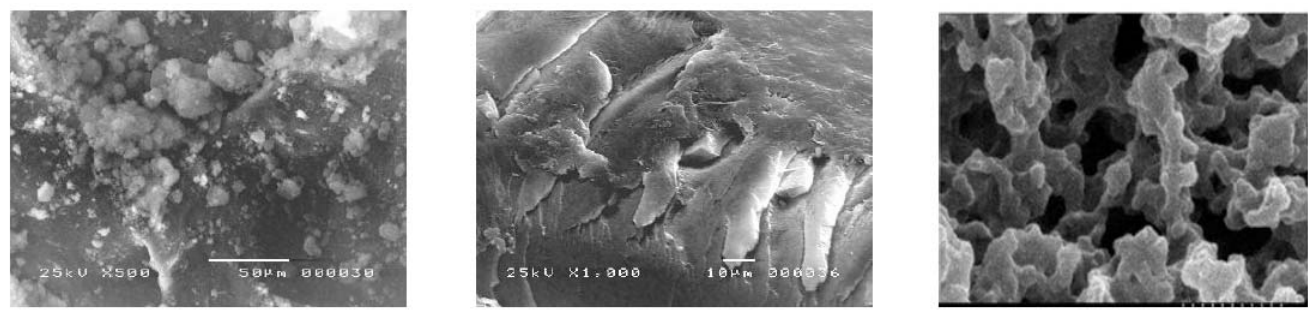

a) SEM of nanosilica b) SEM of PAAm

c) SEM of PVA

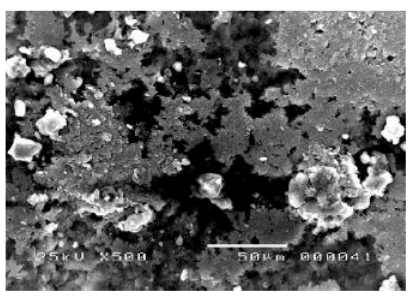

d) MC3 nanocomposite

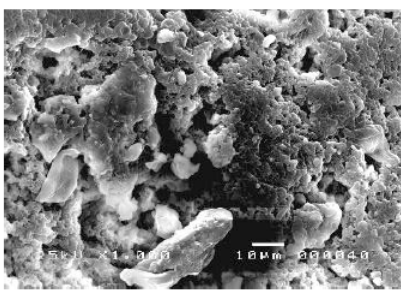

e) MB3 nanocomposite

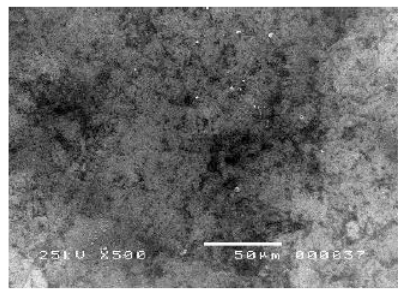

f) MA3 nanocomposite

Figure 3: Scanning electron micrographs. 
PAAm as shown in (Table 2). The main reason for these results is that silica nanoparticles can interact with PAAm molecules by the formation of hydrogen bonds between the silanol functions of the silica and the amide groups in the PAAm molecular chain. These interactions can reinforce the polymer structure and increase the thermal stability. With increasing concentration of silica, the fraction of amide groups interacting with the nanoparticles becomes stronger, consequently, the movement of polymer chains is limited, and the thermal stability increases [36].

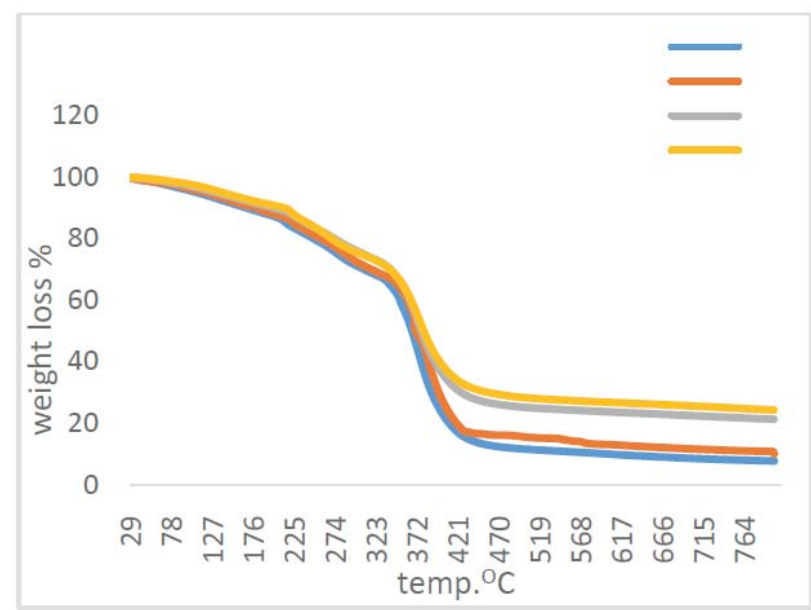

Figure 4: TGA of PAAm in presence of different concentration of nanosilica.

Depending on this results we selected the concentration $0.5 \%$ of nanosilica to study the effect of different ratio of PAAm/PVA blend as shown in (Figure 5). The addition of PVA with different ratio to PAAm decreased the thermal stability of PAAm. This could correspond to structural decomposition of polymer blends and higher weight loss in this region which indicated the existence of chemical degradation. Relevant data are shown in (Table 3). This higher thermal stability was observed for 3:1 blend sample by TGA was due to the intermolecular cross-linking reaction giving highly compatible impact blend system. In contrast in ref. [31, 37, 38] as the concentration of PVA increase the thermal stability decreased in the blend. The data obtained by TGA indicated the possibility of a strong hydrogen bonding between PAAm and PVA due to $-\mathrm{CONH}_{2}$ groups in PAAm and $\mathrm{OH}$ group in PVA, which was also confirmed by our FTIR study.

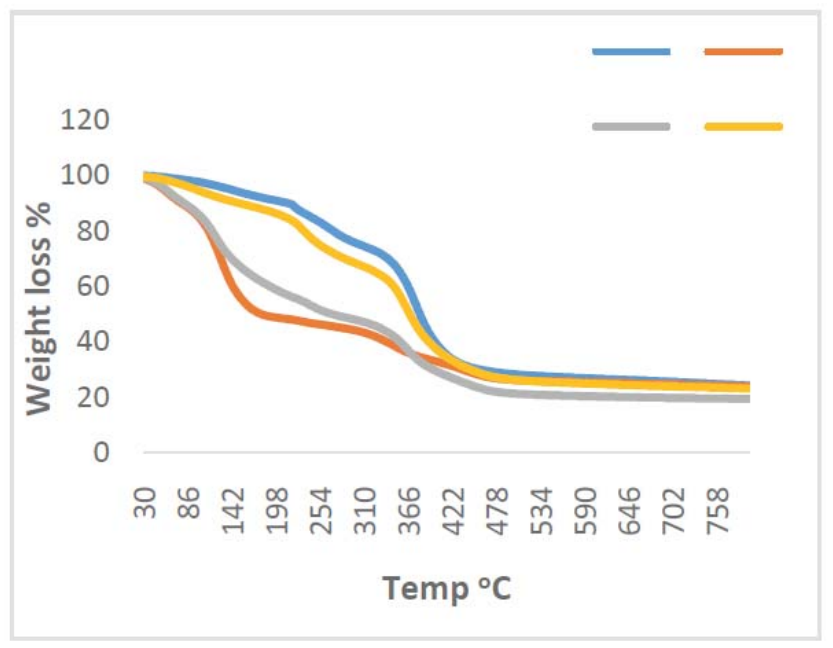

Figure 5: Effect of different ratio of PAAm/ PVA blend at constant concentration of nanosilica $(0.5 \%)$.

By studying the PAAm/PVA with ratio 3:1 with different concentration of nanosilica, it was observed by increasing the concentration of nanosilica the thermal stability was increased as shown in (Figure 6). The main reason for these results is that silica nanoparticles can interact with this blend molecules by the formation of hydrogen bonds between the silanol functions of the silica and the amide groups in the PAAm molecular chain in the blend [36] as shown in (Table 4).

From TGA, we may conclude that the thermal stability regions of the PAAm/nanosilica samples are higher than the PAAm pure and its stability is enhanced by increasing the concentration of nanosilica in PAAm polymer matrix and it becomes more stable at $0.5 \%$. of nanosilica.

\subsection{The Electrical Conductivity of PAAm/ PVA/SiO Nanocomposites}

(Figure 7) shows the temperature dependence of the dc conductivity of $\mathrm{PAAm} / \mathrm{SiO}_{2}$ nanocomposites

Table 2: Effect of Different Concentration of Nanosilica on PAAm

\begin{tabular}{|c|c|c|c|c|}
\hline Sample & $\mathbf{T}_{\mathbf{1 0}}$ & $\mathbf{T}_{\mathbf{5 0}}$ & $\mathbf{T}_{\max }$ & Char Residue \% \\
\hline \hline M0 & 167 & 366 & 375 & 7.61 \\
\hline M1 & 182 & 370 & 373 & 21.11 \\
\hline M2 & 199 & 377 & 373 & 24.16 \\
\hline M3 & 213 & 380 & 376 & 10 \\
\hline
\end{tabular}


Table 3: Effect of Different Ratio of PAAm/ PVA Blend at Constant Concentration of Nanosilica (0.5 \%)

\begin{tabular}{|c|c|c|c|c|}
\hline Sample & $\mathbf{T}_{\mathbf{1 0}}$ & $\mathbf{T}_{\mathbf{5 0}}$ & $\mathbf{T}_{\max }$ & Char Residue \% \\
\hline \hline M3 & 202 & 381 & 376.37 & 24.16 \\
\hline MA3 & 140 & 358 & 365.56 & 23.13 \\
\hline MB3 & 70 & 258 & 364.21 & 19.39 \\
\hline MC3 & 68 & 169 & 438.52 & 18.74 \\
\hline
\end{tabular}

samples. The pattern indicates an increase in conductivity with rise in temperature. This type of temperature dependence indicates that the electrical conduction in the samples is a thermally activated transport process governed by Arrhenius relation $\sigma_{\mathrm{dc}}=$ $\sigma_{0} \exp \left(-E_{a} / k T\right)$ where $\sigma_{0}$ is the dc conductivity preexponential factor and $E_{a}$, the activation energy [39].

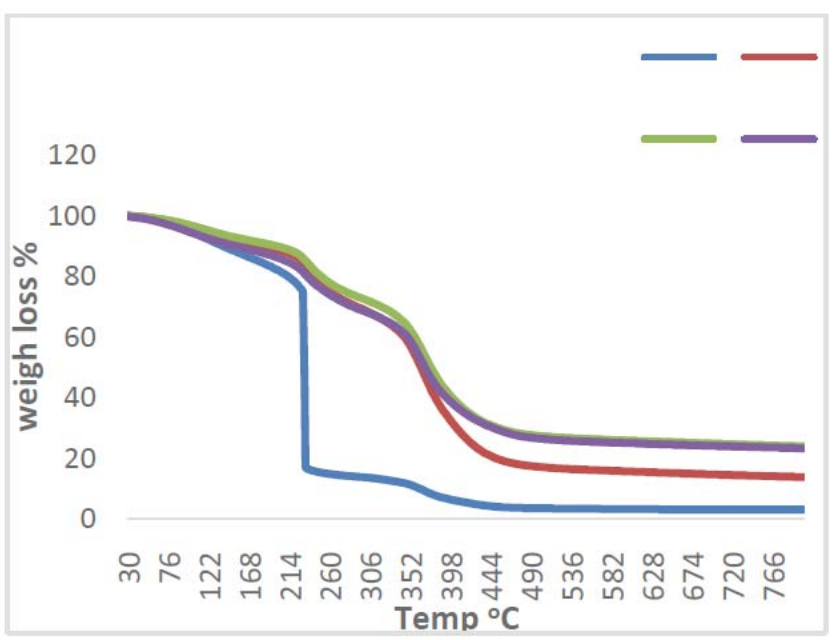

Figure 6: Effect of different concentration of nanosilica of PAAm /PVA blend at constant Ratio (3:1).

Figure 8 shows the variation of the d.c. conductivity values at two different temperatures $\left(25,80^{\circ} \mathrm{C}\right)$ for the PAAm/silica nanocomposites versus the contents of silica (wt\%). The Figure elucidates that the of the nanocomposites is higher than that of the neat PAAm, also it increases with increasing the silica content in the nanocomposites till $0.25 \%$ of the silica content then decrease at high concentration $(0.5 \%)$. The silica surface contains hydroxyl groups, which makes its surface polar. According to Wolff and Wang [40], the surface energies of silica are characterized by a lower dispersive component and a higher specific component. The lower dispersive components cause weak polymer-filler interactions while higher specific component leads to strong interactions among the silica particles. Moreover, at the same time, the polar surface of silica enhances filler-filler interactions also resulting in strong intermolecular hydrogen bonds between hydroxyl groups of silica [41, 42]. Due to such strong interactions, it can aggregate tightly resulting in its poor dispersion in the PAAm nanocomposites which explains the decrease in the with the increase of silica filler contents at higher concentration of the silica [43, 44].

The effect of the PVA weight fraction on electrical conductivity of PAAm/PVA/SiO 2 blend nanocomposites at two temperatures $\left(25,80^{\circ} \mathrm{C}\right)$ is shown in Figure $\mathbf{9}$. The figure shows that the electrical conductivity increases with increasing the weight fraction of PVA. It is known that under the applied electrical field the PVA, similarly as many other dielectric polymers, is polarized [45]. The polarization is due to the space charge formed by the carriers which were injected to the polymer from the electrodes and trapped in the bulk, dipolar orientation, migrational polarization, etc.

\section{CONCLUSION}

Polyacrylamide (PAAm) nanosilica nanocomposites were prepared having different ratios of nanosilica $(0.125 \%, 0.25 \%$, and $0.5 \%)$. Compatible PAAm/PVA blends were prepared successfully using solution-cast

Table 4: Effect of Different Concentration of Nanosilica of PAAm /PVA Blend at Constant Ratio (3:1)

\begin{tabular}{|c|c|c|c|c|}
\hline Sample & $\mathbf{T}_{10}$ & $\mathbf{T}_{\mathbf{5 0}}$ & $\mathbf{T}_{\max }$ & Char Residue\% \\
\hline \hline MA0 & 136 & 230 & 229 & 3.03 \\
\hline MA1 & 178 & 363 & 368 & 13.69 \\
\hline MA2 & 197 & 375 & 366.91 & 23.81 \\
\hline MA3 & 150 & 368 & 365.56 & 23.13 \\
\hline
\end{tabular}




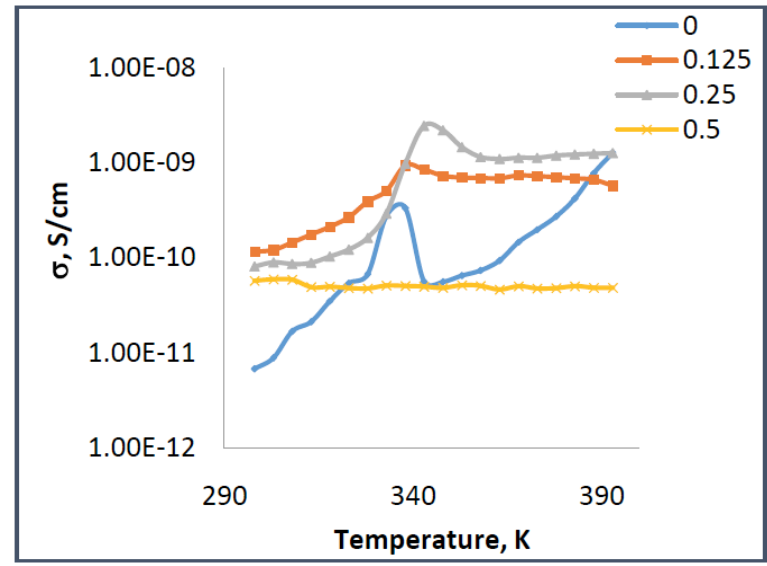

Figure 7: Variation of electrical conductivity of the $\mathrm{PAAm} / \mathrm{SiO}_{2}$ nanocomposites with the temperature.

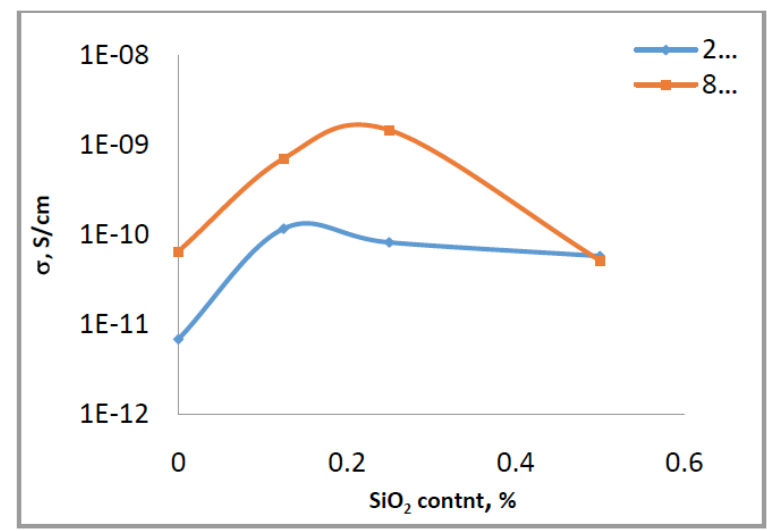

Figure 8: Effect of silica content on the Electrical conductivity of the PAAm $/ \mathrm{SiO}_{2}$ nanocomposites at two different temperatures.

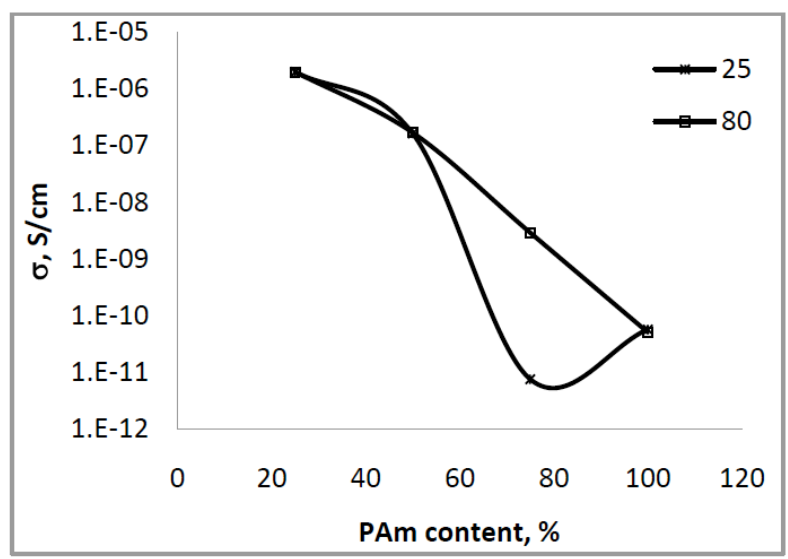

Figure 9: The effect of PVA content on the electrical conductivity of the PAAm/PVA /SiO2 nanocomposites at 0.5 silica content.

technique. FTIR analysis confirmed the conclusion about the specific hydrogen bonding interaction between $-\mathrm{CONH}_{2}$ groups in PAAm and $-\mathrm{OH}$ group in PVA.X-ray diffractions shows the presence of a strong broad peak centered at $22^{\circ}(2 \theta)$ confirms the amorphous nature of silica which is supposed to be the characteristic of $\mathrm{SiO}_{2}$. Due to this hydrogen bonding the thermal stability and electrical conductivity were improved. It was found as the concentration of nanosilica $(0.5 \%)$ increase the conductivity increases and the electrical conductivity increases with increasing the weight fraction of PVA.

\section{REFERENCES}

[1] Devendral K, Rangaswamy T. Evaluation of thermal properties of E-Glass/Epoxy Composites filled by different filler materials. IJCER 2012; 2: 1708-14.

[2] Vinod VS, Varghese S, Alex R, Kuriakose B. Effect of aluminum powder on filled natural rubber composites. Rubber Chem Technol 2000; 74: 236-48. http://dx.doi.org/10.5254/1.3544947

[3] Hashim A, Husaien M, Ghazi JH, Hakim H. Characterization of (polyvinyl alcohol - polyacrylamide -pomegranate peel) composite so as biocomposites materials. Universal J Phys Appl 2013; 1: 242-4.

[4] Zikry AAF. Dielectric behavior of silica/polyacrylamide nanocomposites. Int J Polym Mater 2008; 57: 383-95. http://dx.doi.org/10.1080/00914030701729057

[5] Jia X, Li Y, Cheng Q, Zhang S, Zhang B. Preparation and properties of poly(vinyl alcohol)/silica nanocomposites derived from copolymerization of vinyl silica nanoparticles and vinyl acetate. Eur Polym J 2007; 43: 1123-31. http://dx.doi.org/10.1016/i.eurpolymj.2007.01.019

[6] Wu Y, Wu C, Li Y, Xu T, Fu Y. PVA-silica anion-exchange hybrid membranes prepared through a copolymer crosslinking agent. J Membr Sci 2010; 350: 322-32. http://dx.doi.org/10.1016/j.memsci.2010.01.007

[7] Xie Z, Hoang M, Duong T, Ng D, Dao B, Gray S. Sol-ge derived poly(vinyl alcohol)/maleic acid/silica hybrid membrane for desalination by pervaporation. J Membr Sci 2011; 383: 96-103.

http://dx.doi.org/10.1016/j.memsci.2011.08.036

[8] Shen YD, Zhao YN, Li XR. Polyacrylate/silica hybrids prepared by emulsifier-free emulsion polymerization and the sol-gel process. Polym Bull 2009; 63: 687-98. http://dx.doi.org/10.1007/s00289-009-0117-0

[9] Zulfikar MA, Mohammad AW, Kadhum AA, Hilal N. Synthesis and characterization of poly(methyl methacrylate)/SiO2 hybrid membrane. Materials Science and Engineering: A 2007; 452.

http://dx.doi.org/10.1016/j.msea.2006.10.147

[10] Irani M, Keshtkar AR, Mousavian MA. Removal of Cd(II) and $\mathrm{Ni}$ (II) from aqueous solution by PVA/TEOS/TMPTMS hybrid membrane. Chem Eng J 2011; 175: 251-9. http://dx.doi.org/10.1016/j.cej.2011.09.102

[11] Razavi S, Sabetghadam A, Mohammadi T. Dehydration of isopropanol by PVA-APTEOS/TEOS nanocomposite membranes. Chem Eng Res Des 2011; 89: 148-55. http://dx.doi.org/10.1016/j.cherd.2010.06.004

[12] Zhao Y-N. Preparation of poly(vinyl alcohol)/silica nanocomposties by sol-gel method. e-Polymer 2013; 13: 115-23.

[13] Bhattacharya M, Chaudhry S. High-performance silica nanoparticle reinforced poly (vinyl alcohol) as templates for bioactive nanocomposites. Mater Sci Eng C Mater Biol Appl 2013; 33: 2601-10. http://dx.doi.org/10.1016/j.msec.2013.02.029

[14] Coleman MM. Specific interactions and miscibility of polymer blends. Technomic 1991; 20. 
[15] Abdel Kader FH, Shehao AM, Aboellil MS, Mahmood KH. Dielectric relaxation and a.c. conductivity of polyvinyl alcohol /sodium carboxy methyl cellulose and their blends. J Polym Mater Sci 2005; 22: 349-62.

[16] Tanwar A, Gupta KK, Singh PJ, Vijay YK. Dielectric parameters and ac conductivity of pure and doped poly (mehyl methacrylate) films at microwave frequencies. Bull Mater Sci 2006; 29: 397-401. http://dx.doi.org/10.1007/BF02704142

[17] Jones AA. Molecular level model for motion and relaxation in glassy polycarbonate. Macromolecules 1985; 18: 1902. http://dx.doi.org/10.1021/ma00147a014

[18] O'Gara JF, Jones AA, Hung CC, Inglefield PT. Temperature dependence of local motions in glassy polycarbonate from carbon and proton nuclear magnetic resonance. Macromolecules 1985; 18: 1117-23.

[19] Tormalla PJ. Spin Label and Probe Studies of Polymeric Solids and Melts. Macro Sci Rev Macro Chem 1979; C17: 297.

http://dx.doi.org/10.1080/00222357908080913

[20] Rao KVS, Rao SS, Rao SUV. Thermally stimulated discharge current studies in thin films of polyacrylamide. Crystal Res Technol 1992; 27: 875-81.

[21] Rao SS, Rao KVS, Shareefuddin Md, Chary MN, Reddy KN, Rao UVS. Electrical conduction in a polyblend of polyvinyl pyrrolidone and polyacrylamide. Crystal Res Technol 1992; 27: 973-9.

[22] Satyanarayana RKV, Subba Rao UV, Narasimha RVV. Electrical conduction mechanism in polyacrylamide films. $J$ Materials Science Letters 1990; 9: 3-4. http://dx.doi.org/10.1007/BF00722850

[23] Ikezaki K. Materials Research Society 2001; 223-8522.

[24] Rao VVRN, Krishna KJ, Rao BS, Thermally stimulated depolarization currents in poly(vinyl alcohol) films. Acta Polymerica 1992; 43: 68-71.

[25] Prasad KR. Determination of the trapping parameters of TL glow curves of polyacrylamide (PAAM)-polyvinylalcohol (PVA) polyblends by employing computer simulation. Int $\mathrm{J}$ Sci Eng Technol 2012; 1: 301-5.

[26] Demchenko O, Zheltonozhskaya T, Guenet JM, Filipchenko S, Syromyatnikov V. Properties of poly(vinyl alcohol)-graftpolyacrylamide copolymers depending on the graft length. 2 . Thermal properties in the bulk state. Macromol Symp 2003; 203: 183-92.

[27] Goyal A, Kunio H, Hidehiko O, Mandula. Properties and Reactivity of Sugarcane Bagasse ash. http://soil.en.a.utokyo. ac.jp/jsidre/search/PDFs/07/07006-35.pdf, 2007.

[28] Hariharan V, Sivakumar G. Studies on synthesized nanosilica obtained from bagasse ash. Int $\mathrm{J}$ Chem Tech Res 2013; 5: 1263-6.

[29] Sivakumar G, Amutha K. Studies on Silica Obtained from Cow Dung Ash. Advanced Materials Research 2012; 584: 470-473.

http://dx.doi.org/10.4028/www.scientific.net/AMR.584.470

[30] Chen CH, Wang FY, Mao CF, Liao WT, Hsieh CD. Studies of chitosan: II. Preparation and characterization of chitosan/poly(vinyl alcohol)/gelatin ternary blend films. Int J Biol Macromol 2008; 43: 37-42.

http://dx.doi.org/10.1016/j.ijbiomac.2007.09.005
[31] Patel G, Sureshkumar MB. Preparation of PAM/PVA blending films by solution cast technique and its characterization: a spectroscopic study. Iranian Polym J 2014; 23: 153-62.

[32] Tokarev I, Tokareva I, Minko S. Gold-Nanoparticle-Enhanced Plasmonic Effects in a Responsive Polymer Gel. Adv Mater 2008; 20: 2730-2734.

http://dx.doi.org/10.1002/adma.200702885

[33] Xiang $\mathrm{Y}$, Chen D. Preparation of a novel $\mathrm{pH}$-responsive silver nanoparticle/poly(HEMA-PEGMA-MAA) composite hydrogel. Eur Polym J 2007; 43: 4178-4187. http://dx.doi.org/10.1016/j.eurpolymj.2007.08.005

[34] Xia HS, Wang Q. Preparation of conductive polyaniline/nanosilica particle composites through ultrasonic irradiation. J Appl Polym Sci 2003; 87: 1811-1817. http://dx.doi.org/10.1002/app.11627

[35] Bershtein VA, Egorova LM, Yakushev PN, Pissis P, Sysel P, Brozova L. Molecular dynamics in nanostructured polyimidesilica hybrid materials and their thermal stability. J Polym Sci Part B Polym Phys 2002; 40: 1056-69.

[36] Zhu D, Wei L, Wang B, Feng Y. Aqueous Hybrids of Silica Nanoparticles and Hydrophobically Associating Hydrolyzed Polyacrylamide Used for EOR in High-Temperature and High-Salinity Reservoirs. Energies 2014; 7: 3858-3871. http://dx.doi.org/10.3390/en7063858

[37] El-Kader FH, Gafer SA, Basha AF, Bannan SI, Basha MAF. Thermal and optical properties or gelatin / poly (vinyl alcohol) blends. J Appl Polym Sci 2010; 118: 413-20.

[38] Aggour YA. Thermal degradation studies of poly(ethylene glycol allenyl-methyl ether)s and their copolymers with styrene. Polym Degrad Stab 1996; 51: 265-269. http://dx.doi.org/10.1016/0141-3910(95)00205-7

[39] Motawie AM, Madany MM, El-Dakrory AZ, Osman HM, Ismail EA, Badr MM, Abulyazied DE. Electrophysical characteristics of polyurethane/organo-bentonite nanocomposites. Egyptian Journal of Petroleum (EGYJP) 2014; 23; 379-387.

http://dx.doi.org/10.1016/j.ejpe.2014.09.005

[40] Ou YC, Yu ZZ, Vidal A, Donnet JB. Effects of alkylation of silica filler on rubber reinforcement. Rubb Chem Tech 1994; 67: 834-44.

[41] Madani M. Effect of silica type and concentrations on the physical properties of EPDM cured by $\gamma-$ irradiation. Mol Phys 2008; 106: 849-57.

[42] Leroux $\mathrm{C}$, Mur $\mathrm{P}$, Rochat $\mathrm{N}$, et al. Characterization and modeling of nanometric SiO2 dielectrics. Microelectron Eng 2004; 72: 121-4.

[43] Perepechko II. An Introduction to Polymer Physics. Mir Publisher, Moscow, English edn, 1981.

[44] Lawandy SN, Abdel-Nour KN. Dielectric properties and stress-strain measurements of chloroprene rubber based on different carbon black fillers. J Appl Polym Sci 1984; 31: 841.

http://dx.doi.org/10.1002/app.1986.070310308

[45] Rudko GYu, Kovalchuk AO, Bondarenko VA, Fediv VI, Gule EG. Tunable electrophysical properties of composites nanoCdS/polyvinyl alcohol. Mater Chem Phys 2014; 148: 77-81. 